\title{
Comparison of 9-month angiographic outcomes of Resolute zotarolimus-eluting and everolimus-eluting stents in a real world setting of coronary intervention in Korea
}

Joo Myung Lee ${ }^{1}$, Tae-Jin Youn ${ }^{2 *}$, Jin Joo Park², II-Young Oh², Chang-Hwan Yoon², Jung-Won Suh², Young-Seok Cho ${ }^{2}$, Goo-Yeong Cho², In-Ho Chae ${ }^{2}$ and Dong-Ju Choi ${ }^{2}$

\begin{abstract}
Background: Clinical outcomes of new-generation drug-eluting stents (DES), Everolimus-eluting stent (EES) or Resolute zotarolimus-eluting stent (R-ZES), have been reported. However, angiographic follow-up data of new-generation DES are limited, especially in Asians. We investigated the angiographic and clinical outcomes of EES and R-ZES in a real-world setting of Korean patients.

Methods: Angiographic and clinical outcomes of 679 patients (866 lesions) who had been treated with EES or R-ZES from Jun 2008 to May 2010 were evaluated. The primary analysis was to compare in-segment late loss at 9 months and the secondary analyses were to compare the clinical outcomes.

Results: In-segment late loss at 9-month follow-up angiography was $0.23 \pm 0.52 \mathrm{~mm}$ for EES and $0.29 \pm 0.64 \mathrm{~mm}$ for R-ZES ( $p=0.248)$. In addition, the rate of binary restenosis did not show between-group differences ( $5.8 \% \mathrm{vs}$. $6.8 \%$ for EES and R-ZES, respectively, $p=0.716$ ). During a median follow-up of 33 months, there were no significant differences in Kaplan-Meier estimates of target lesion failure (TLF) (7.5\% vs. 7.9\% for EES and R-ZES, respectively, $\mathrm{p}=0.578$ ) and patient-oriented composite outcomes (POCO including all-cause death, any myocardial infarction, and any revascularization, $22.8 \%$ vs. $20.1 \%, p=0.888$ ). The adjusted hazard ratios for TLF and POCO were 0.875 $(95 \% \mathrm{Cl} 0.427-1.793 ; \mathrm{p}=0.715)$ and $1.029(95 \% \mathrm{Cl} 0.642-1.650 ; \mathrm{p}=0.904)$, respectively, for EES over R-ZES in the propensity score matched group analysis.

Conclusions: In Korean patients undergoing new-generation DES implantation for coronary artery disease, EES and R-ZES showed similar angiographic outcomes at 9 months and comparable clinical outcomes during 2.8 years of median follow-up.
\end{abstract}

Keywords: Percutaneous coronary intervention, Drug eluting stent, Late loss, Quantitative coronary angiography, Resolute zotarolimus-eluting stent, Everolimus-eluting stent

\footnotetext{
* Correspondence: ytjmd@snubh.org

${ }^{2}$ Division of Cardiology, Department of Internal Medicine, College of Medicine, Seoul National University and Cardiovascular Center, Seoul National University Bundang Hospital, Seongnam-si, Gyeonggi-do, Korea Full list of author information is available at the end of the article
} 


\section{Background}

In the era of drug eluting stents (DES), angiographic and clinical measures of restenosis have been substantially reduced [1-3]. However, long-term clinical outcome analyses have raised concerns about the serious safety problem of stent thrombosis [3-5], which has been known to be associated with allergic and inflammatory reactions to polymers and incomplete strut endothelialization [6-8]. As a consequence, DES with a new-generation polymer were developed, including the Xience $\mathrm{V}^{\mathrm{m}}$ everolimus-eluting stent (EES) (Abbott CardioVascular, CA, USA) and the Resolute zotarolimus-eluting stent (R-ZES) (Medtronic CardioVascular, CA, USA). These stents use a cobalt chromium based strut with permanent but biocompatible polymers (poly-vinyl-idene fluoride-co-hexafluoropropylene [PVDF-HFP] and Biolinx, respectively).[9] Recently, results of large scale randomized controlled trials (RCTs) with an 'all-comers' design have been reported comparing the efficacy and safety of EES and R-ZES [10-12]. However, angiographic outcomes of these two stents have been limited. In addition, even the RCTs with an 'all-comers' design do not include all consecutive patients who are encountered in every day clinical practice [13]. Therefore, the purpose of this study was to evaluate and compare the angiographic and clinical outcomes of EES and R-ZES in the unselected Korean patient population.

\section{Methods}

\section{Patients population}

From June 2008 to May 2010, we prospectively identified 734 patients who were treated by percutaneous coronary intervention (PCI) with either EES or R-ZES for chronic stable coronary artery disease or acute coronary syndrome, including myocardial infarction (MI) with or without ST-segment elevation. Patients who were treated with at least one DES were enrolled in the 'DES registry of the Seoul National University Bundang Hospital (DES-SNUBH)' at the catheterization laboratory. There were no restrictions or exclusion criteria for enrollment regarding the reference vessel diameter, total numbers of treated lesion or vessels, numbers of stents implanted, lesion length, referral diagnosis, or comorbidities. Out of 734 patients, 55 patients who were treated with both EES and R-ZES were excluded from the clinical and angiographic outcomes analyses. Therefore, the main analyzed cohort was the remaining 679 patients with 866 lesions (EES 405 patients with 500 lesions; R-ZES 274 patients with 366 lesions) from the registry. Among the main analyzed cohort, 138 patients of EES group (34.2\%) and 114 patients of R-ZES group (41.6\%) were also enrolled to other Korean multicenter registries (the EXCELLENT and RESOLUTE-Korea registries) under same inclusion and no exclusion criteria [14]. All patients provided written informed consent, and the study protocol was approved by the institutional review board of Seoul National University Bundang Hospital.

\section{Interventional procedures}

Coronary interventions were performed according to current standard techniques. The choice of the stent, predilatation, post-stenting adjunctive balloon inflation, and the use of intravascular ultrasound or glycoprotein IIb/IIIa inhibitors were all left to the operators' discretion. All patients received at least $100 \mathrm{mg}$ of aspirin before the procedure. A loading dose of 300 to $600 \mathrm{mg}$ of clopidogrel was administered to all patients who were not on clopidogrel prior to the procedure. After the procedure, all patients were given aspirin (at least $100 \mathrm{mg} /$ day) indefinitely and clopidogrel $(75 \mathrm{mg} /$ day) for at least 1 year after index procedure. During the procedure, unfractionated heparin at a dose of 70 to $100 \mathrm{U}$ per kilogram of body weight was administered to achieve and maintain an activated clotting time of more than 250 seconds.

\section{Clinical and angiographic follow-up and quantitative coronary angiography}

Clinical follow-up after PCI was recommended at 1 month, 6 months, and 1 year and annually thereafter. Angiographic follow-up was routinely recommended at 9 months, post-PCI or earlier if patients complained of any ischemic symptoms or if noninvasive evaluation suggested the presence of ischemia. The follow-up angiography was performed systematically and in a routine manner, unless the patient rejected the follow-up procedure or the patient's condition was not suitable to undergo coronary angiography. All patients enrolled in this registry provided a written informed consent not only for the enrollment but also for the follow-up angiography. Coronary angiography obtained at baseline, immediately postprocedure, and at follow-up were analyzed quantitatively (by quantitative coronary angiography [QCA]) using the Cardiovascular Angiography Analysis System (CAAS) II (Pie Medical Imaging, Maastricht, Netherlands) by an experienced technician who was not aware of the study purpose. The minimum lumen diameter (MLD), reference vessel diameter, percent stenosis, acute gain (defined as the difference in MLD before and after stent implantation), late lumen loss (defined as the difference between the postprocedure and follow-up MLD), and binary restenosis (defined as stenosis of $50 \%$ or more at follow-up angiography) were measured [15]. All QCA measurements of the target lesion were obtained in the in-stent zone, and over the entire segment including the stent and its $5-\mathrm{mm}$ proximal and distal margins (in-segment zone).

\section{Definitions and outcomes analysis}

The stent-related clinical outcome was target lesion failure (TLF), defined as a composite of cardiac death, MI 
(not clearly attributed to a nontarget vessel), or a clinically indicated target lesion revascularization by percutaneous or surgical methods [16]. The patient-related clinical outcome was patient-oriented composite outcome (POCO) which included all-cause mortality, any MI (including nontarget vessel territory), and any revascularization (including all target and nontarget vessels, regardless of percutaneous or surgical methods) [16]. Other clinical outcomes, including MI, stent thrombosis, target lesion revascularization, and target vessel revascularization were defined as according to Academic Research Consortium (ARC) definitions [16]. Patients with complex lesions (considered an off-label indication for use of both DES) were defined as having at least one of the following characteristics: serum creatinine concentration $\geq 140 \mathrm{umol} / \mathrm{L}(1.6 \mathrm{mg} / \mathrm{dL})$; left ventricular ejection fraction (LVEF) < $30 \%$; an acute MI within the previous 72 hours; more than one lesion per vessel; two or more vessels treated with a stent; a lesion greater than $27 \mathrm{~mm}$; or a bifurcated lesion, bypass graft, in-stent restenosis, unprotected left main coronary artery, presence of thrombus, or total occlusion $[11,17]$.

\section{Statistical analysis}

Statistical analyses were performed in three parts. The primary analysis was to compare the angiographic outcomes at 9 months and the secondary analyses were to compare the clinical outcomes. Comparison of angiographic outcomes between two groups was performed in the crude population. Clinical outcome analysis was perfomed on 1) the crude population and 2) the propensity score matched population. Event rates of clinical outcomes were expressed as incidence density (i.e. Kaplan-Meier estimates) and the log-rank or Breslow test was used to compare betweengroup differences. For the subgroup analysis of TLF, Cox proportional hazard model was used to calculate the hazard ratio of EES compared with R-ZES, and interaction $p$ values between treatment and each subgroup. Since differences in baseline characteristics could impact the development of clinical outcomes, a 1:1 matched analysis without replacement was performed using propensity score which was calculated from the model with 23 covariates (Additional file 1: Table S1). The log-odds of the probability that a patient received an R-ZES were modeled as a function of the confounders. A caliper width of 0.6 SDs was used because this value has been shown to eliminate almost $90 \%$ of the bias in the observed confounders [18]. Success of the propensity score matching was assessed by calculating percentage standardized differences of the baseline characteristics. A less than $10 \%$ difference supports the assumption of a balance between matched groups [19]. Propensity score adjusted stratified Cox proportional hazard regression model was fitted to compare the clinical outcomes of the matched EES and R-ZES groups. All probability values were two-sided and p-values $<0.05$ were considered statistically significant. The statistical package SPSS, version 18.0 (SPSS Inc., Chicago, IL, USA) and R programming language, version 2.12.2 ( $\mathrm{R}$ Foundation for Statistical Computing) were used for statistical analyses.

\section{Results}

Baseline clinical and angiographic characteristics

During the study period, a total of 1,508 patients received PCI in our institution. One hundred and eighty-one

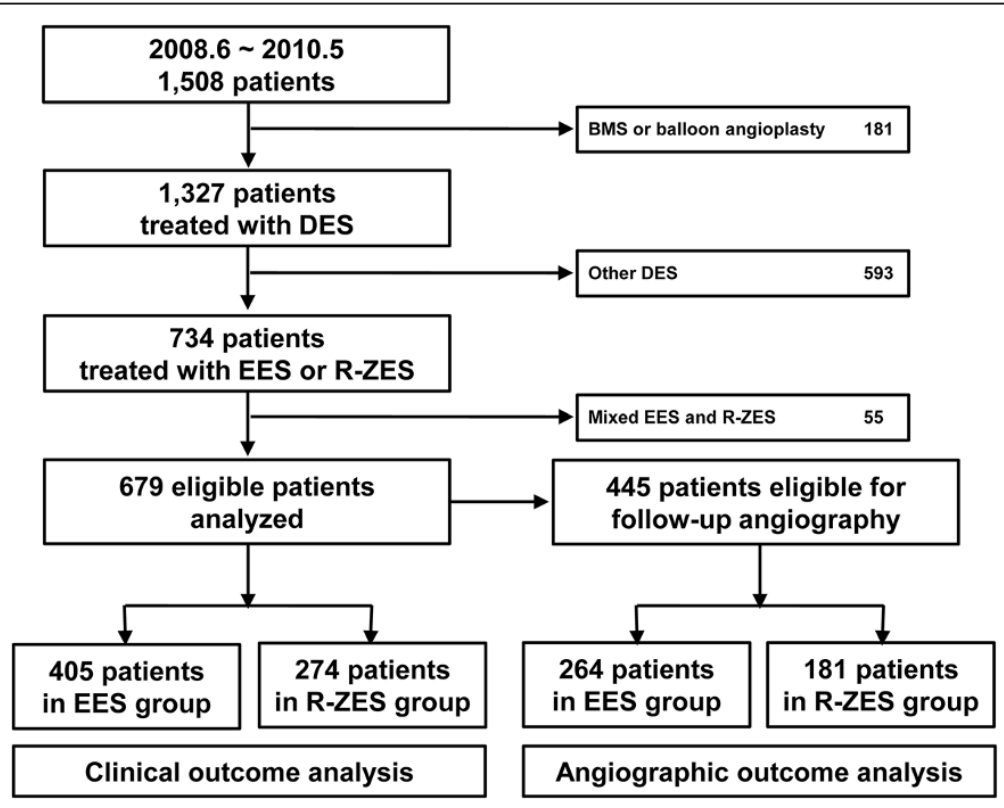

Figure 1 Flow of participants diagram. Abbreviations: EES, everolimus-eluting stent; R-ZES, Resolute zotarolimus eluting-stent. 
patients were treated with bare-metal stent or balloon angioplasty. Of the remaining 1,327 patients who were treated with DES, 734 patients (55.3\%) were treated with EES or R-ZES. Fifty-five patients were excluded since they were treated with EES and R-ZES simultaneously. The flow of participants for the study is presented in Figure 1. The cohort used for the main analysis consisted of 679 patients with 866 lesions (EES 500 lesions/405 patients, R-ZES 366 lesions/274 patients). The baseline clinical characteristics were similar in both groups, except that the proportion of patients with multivessel disease was higher in R-ZES group (Table 1). A total of 501 of 679 (73.8\%) patients were classified as complex, which was distributed similarly in both group. EES was more frequently implanted into the left main coronary lesion and the in-stent restenosis lesion than R-ZES; however, R-ZES was more often used for small vessel lesion. As a consequence, the mean stent diameter was significantly smaller in the R-
ZES group. The mean in-stent and in-segment MLDs after the procedure were also smaller in R-ZES group than in EES group, despite the similar acute gains in the two groups (Table 2).

\section{Angiographic outcomes and at 9 months}

Angiographic follow-up at 9 months was available in 445 patients with 564 lesions (65.5\%) (Figure 1). Baseline clinical and angiographic characteristics of the patient cohort undergoing QCA analysis at 9 months are listed in Additional file 1: Table S2 and were similar between groups. In-segment late loss was $0.23 \pm 0.52 \mathrm{~mm}$ for EES and $0.29 \pm 0.64 \mathrm{~mm}$ for R-ZES $(\mathrm{p}=0.248)$. In-stent late loss showed similar findings $(0.24 \pm 0.53 \mathrm{~mm}$ for EES vs. $0.29 \pm$ $0.58 \mathrm{~mm}$ for R-ZES, $\mathrm{p}=0.267$ ). In addition, the rate of binary restenosis $(5.8 \%$ vs. $6.8 \%, \mathrm{p}=0.716)$ did not show between-group differences, despite significantly smaller

Table 1 Baseline clinical characteristics of crude population*

\begin{tabular}{|c|c|c|c|}
\hline & EES $(N=405)$ & R-ZES $(N=274)$ & $P$ value \\
\hline Age, years & $63.9 \pm 11.8$ & $64.9 \pm 11.9$ & 0.264 \\
\hline Male & $297(73.3 \%)$ & $197(71.9 \%)$ & 0.680 \\
\hline \multicolumn{4}{|l|}{ Coexisting condition } \\
\hline Diabetes mellitus & $157(38.8 \%)$ & $101(36.9 \%)$ & 0.616 \\
\hline Hypertension & $283(69.9 \%)$ & $172(62.8 \%)$ & 0.056 \\
\hline Dyslipidemia & $140(34.6 \%)$ & $91(33.2 \%)$ & 0.714 \\
\hline Cerebrovascular disease & $35(8.7 \%)$ & $18(6.6 \%)$ & 0.325 \\
\hline Peripheral artery disease & $9(2.2 \%)$ & $9(3.3 \%)$ & 0.398 \\
\hline Chronic renal failure & $15(3.7 \%)$ & $14(5.1 \%)$ & 0.374 \\
\hline \multicolumn{4}{|l|}{ Cardiovascular risk factors } \\
\hline Current smoker & $103(25.4 \%)$ & 77 (28.1\%) & 0.439 \\
\hline Previous $\mathrm{PCl}$ & $69(17.0 \%)$ & $40(14.6 \%)$ & 0.396 \\
\hline Previous CABG & $5(1.2 \%)$ & $5(1.8 \%)$ & 0.531 \\
\hline Previous Ml & $33(8.1 \%)$ & $25(9.1 \%)$ & 0.842 \\
\hline \multicolumn{4}{|l|}{ Clinical indications } \\
\hline Stable angina & $189(46.7 \%)$ & $124(45.3 \%)$ & 0.717 \\
\hline Unstable angina & 99 (24.4\%) & $64(23.4 \%)$ & 0.745 \\
\hline Acute myocardial infarction & 117 (28.9\%) & $86(31.4 \%)$ & 0.485 \\
\hline Emergency PCI for acute STEMI & $41(10.1 \%)$ & $34(12.4 \%)$ & 0.351 \\
\hline Left ventricular ejection fraction & $57.11 \pm 10.40$ & $56.25 \pm 11.71$ & 0.374 \\
\hline Severe LV dysfunction (LVEF < 30\%) & $6(1.5 \%)$ & $7(2.6 \%)$ & 0.317 \\
\hline Multivessel disease & $275(67.9 \%)$ & $207(75.5 \%)$ & 0.031 \\
\hline Complex patient $^{\dagger}$ & $293(72.3 \%)$ & $208(75.9 \%)$ & 0.328 \\
\hline
\end{tabular}

* Data are number (\%), unless otherwise indicated. Plus-minus values are means \pm SD.

${ }^{\dagger}$ Complex patient : Complex patients (= off label use) were defined as having at least one of the following characteristics: serum creatinine concentration of 140 umol/L (1.6 mg/dL) or more; left ventricular ejection fraction < 30\%; an acute myocardial infarction within the previous 72 hours; more than one lesion per vessel; two or more vessels treated with a stent; a lesion longer than $27 \mathrm{~mm}$; or bifurcated lesion, bypass graft, in-stent restenosis, unprotected left main coronary artery, presence of thrombus, or total occlusion.

Abbreviations: CABG coronary artery bypass graft, EES everolimus-eluting stent, $F / U$ follow-up, IQR interquartile range, $L V$ left ventricle, $L V E F$ left ventricular ejection fraction, $M I$ myocardial infarction, $P C l$ percutaneous coronary intervention, $R$-ZES Resolute zotarolimus eluting-stent, STEMI myocardial infarction with ST-segment elevation. 
Table 2 Baseline lesional characteristics and quantitative coronary angiography data of crude population ${ }^{*}$

\begin{tabular}{|c|c|c|c|}
\hline & EES $(N=500)$ & R-ZES $(N=366)$ & $P$ value \\
\hline \multicolumn{4}{|l|}{ Before index procedure } \\
\hline Target vessel location & & & 0.509 \\
\hline Left main & $32(6.4 \%)$ & $11(3.0 \%)$ & \\
\hline LAD & $252(50.4 \%)$ & $168(45.9 \%)$ & \\
\hline LCX & 109 (21.8\%) & $95(26.0 \%)$ & \\
\hline RCA & $135(27.0 \%)$ & $100(27.3 \%)$ & \\
\hline 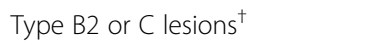 & $315(63.0 \%)$ & $227(62.0 \%)$ & 0.769 \\
\hline In-stent restenosis & $39(7.8 \%)$ & $15(4.1 \%)$ & 0.032 \\
\hline Chronic total occlusion & $14(2.8 \%)$ & $20(5.5 \%)$ & 0.052 \\
\hline Bifurcation $^{\ddagger}$ & $31(6.2 \%)$ & $31(8.5 \%)$ & 0.201 \\
\hline Small vessel $\left.\right|^{\S}$ & 169 (33.8\%) & $167(45.6 \%)$ & 0.001 \\
\hline Long lesion" & $102(20.4 \%)$ & $69(18.9 \%)$ & 0.572 \\
\hline Lesion length, mm & $20.63 \pm 9.89$ & $21.10 \pm 10.32$ & 0.530 \\
\hline Reference diameter, mm & $2.90 \pm 0.59$ & $2.79 \pm 0.58$ & 0.012 \\
\hline Minimum lumen diameter, mm & $0.75 \pm 0.49$ & $0.72 \pm 0.51$ & 0.352 \\
\hline Percent stenosis, \% & $79.60 \pm 15.35$ & $78.03 \pm 17.05$ & 0.162 \\
\hline \multicolumn{4}{|l|}{ After index procedure } \\
\hline Number of stents/lesion & $1.23 \pm 0.47$ & $1.20 \pm 0.43$ & 0.226 \\
\hline Total stent length/lesion, mm & $27.83 \pm 13.33$ & $28.16 \pm 12.55$ & 0.717 \\
\hline Pressure deployment, atm & $15.02 \pm 5.94$ & $15.12 \pm 4.74$ & 0.783 \\
\hline Mean stent diameter/lesion, mm & $3.11 \pm 0.45$ & $2.91 \pm 0.40$ & $<0.001$ \\
\hline \multicolumn{4}{|l|}{ Minimum lumen diameter, mm } \\
\hline In-stent & $2.61 \pm 0.47$ & $2.51 \pm 0.43$ & 0.001 \\
\hline In-segment & $2.60 \pm 0.48$ & $2.49 \pm 0.45$ & 0.001 \\
\hline \multicolumn{4}{|l|}{ Percent stenosis, \% } \\
\hline In-stent & $12.85 \pm 7.00$ & $11.71 \pm 7.11$ & 0.019 \\
\hline In-segment & $12.35 \pm 7.32$ & $11.38 \pm 7.58$ & 0.063 \\
\hline \multicolumn{4}{|l|}{ Acute gain, mm } \\
\hline In-stent & $1.88 \pm 0.61$ & $1.80 \pm 0.55$ & 0.094 \\
\hline In-segment & $1.86 \pm 0.63$ & $1.79 \pm 0.57$ & 0.128 \\
\hline
\end{tabular}

\footnotetext{
"Data are number (\%), unless otherwise indicated. Plus-minus values are means \pm SD.

${ }^{+}$Type B2 or C lesions according to ACC/AHA classification.

* Bifurcation means bifurcated lesion that have been treated solely by drug-eluting stents.

${ }^{\S}$ Small vessel denotes lesion with reference diameter $<2.75 \mathrm{~mm}$.

"Long lesion denotes lesion with length $\geq 28 \mathrm{~mm}$.

Abbreviations: EES everolimus-eluting stent, $L A D$ left anterior descending artery, $L C X$ left circumflex artery, RCA right coronary artery, $R$-ZES Resolute zotarolimus eluting-stent.
}

reference vessel diameter in the R-ZES gropup $(2.88 \pm$ $0.60 \mathrm{~mm}$ vs. $2.77 \pm 0.50 \mathrm{~mm}, \mathrm{p}=0.038$ ) (Table 3 ).

\section{Clinical outcomes up to 3 years of follow-up}

The median follow-up duration after index procedure was 1014 days (33 months, interquartile range 27.0-38.0 months). There were no significant differences in KaplanMeier estimates of TLF (7.5\% in the EES group vs. $7.9 \%$ in the R-ZES group, $\mathrm{p}=0.578)$ or POCO $(22.8 \%$ vs. $20.1 \%$, $\mathrm{p}=0.888$ ). A total of 9 patients developed ARC-defined definite or probable stent thrombosis. Kaplan-Meier estimates of definite or probable stent thrombosis were not significantly different between the groups $(1.5 \% v \mathrm{v}$. $1.8 \% ; \mathrm{p}=0.741$ ) (Figure 2 and Table 4). Detailed descriptions of the cases are presented in Additional file 1: Table S3.

\section{Subgroup analysis}

Exploratory subgroup analyses regarding TLF were performed according to the presence of diabetes, acute myocardial infarction ( $<72$ hours), multivessel PCI, long lesion $(\geq 28 \mathrm{~mm})$, and small vessel $(<2.75 \mathrm{~mm})$. There 
Table 3 Angiographic outcomes with quantitative coronary angiography data at 9 months follow-up*

\begin{tabular}{|c|c|c|c|}
\hline & EES (Lesion $n=324)$ & R-ZES (Lesion $n=240$ ) & $P$ value \\
\hline Number of patients & $264(65.2 \%)$ & $181(66.1 \%)$ & 0.869 \\
\hline \multicolumn{4}{|l|}{ Before index procedure } \\
\hline Lesion length, mm & $20.33 \pm 10.04$ & $20.89 \pm 8.89$ & 0.528 \\
\hline Reference diameter, mm & $2.88 \pm 0.60$ & $2.77 \pm 0.50$ & 0.038 \\
\hline Minimum lumen diameter, $\mathrm{mm}$ & $0.73 \pm 0.50$ & $0.71 \pm 0.53$ & 0.769 \\
\hline Percent stenosis, \% & $80.73 \pm 14.79$ & $77.64 \pm 17.24$ & 0.024 \\
\hline \multicolumn{4}{|l|}{ After index procedure } \\
\hline Total stent length, mm & $27.03 \pm 12.91$ & $28.61 \pm 12.88$ & 0.153 \\
\hline Number of stents/lesion & $1.20 \pm 0.45$ & $1.20 \pm 0.43$ & 0.889 \\
\hline \multicolumn{4}{|l|}{ Minimum lumen diameter, mm } \\
\hline In-stent & $2.60 \pm 0.48$ & $2.53 \pm 0.43$ & 0.061 \\
\hline In-segment & $2.59 \pm 0.50$ & $2.50 \pm 0.46$ & 0.030 \\
\hline \multicolumn{4}{|l|}{ Percent stenosis, \% } \\
\hline In-stent & $13.03 \pm 6.92$ & $11.17 \pm 6.26$ & 0.001 \\
\hline In-segment & $12.60 \pm 7.20$ & $11.27 \pm 7.53$ & 0.037 \\
\hline \multicolumn{4}{|l|}{ Acute gain, mm } \\
\hline In-stent & $1.89 \pm 0.64$ & $1.83 \pm 0.56$ & 0.284 \\
\hline In-segment & $1.87 \pm 0.67$ & $1.80 \pm 0.60$ & 0.237 \\
\hline \multicolumn{4}{|l|}{ Follow-up procedure } \\
\hline \multicolumn{4}{|l|}{ Minimum lumen diameter, $\mathrm{mm}$} \\
\hline In-stent & $2.37 \pm 0.66$ & $2.23 \pm 0.64$ & 0.017 \\
\hline In-segment & $2.36 \pm 0.66$ & $2.20 \pm 0.66$ & 0.006 \\
\hline \multicolumn{4}{|l|}{ Percent stenosis, \% } \\
\hline In-stent & $20.65 \pm 17.52$ & $20.50 \pm 19.23$ & 0.925 \\
\hline In-segment & $19.41 \pm 17.30$ & $20.68 \pm 19.19$ & 0.431 \\
\hline \multicolumn{4}{|l|}{ Late lumen loss, mm } \\
\hline In-stent & $0.24 \pm 0.53$ & $0.29 \pm 0.58$ & 0.267 \\
\hline In-segment & $0.23 \pm 0.52$ & $0.29 \pm 0.64$ & 0.248 \\
\hline \multicolumn{4}{|l|}{ Loss index } \\
\hline In-stent & $0.19 \pm 0.78$ & $0.09 \pm 0.57$ & 0.129 \\
\hline In-segment & $0.15 \pm 0.81$ & $0.07 \pm 0.99$ & 0.093 \\
\hline \multicolumn{4}{|l|}{ Binary restenosis, $\%$} \\
\hline In-stent & $18(5.8 \%)$ & $15(6.8 \%)$ & 0.716 \\
\hline In-segment & 17 (5.6\%) & $15(6.9 \%)$ & 0.582 \\
\hline
\end{tabular}

* Among a total of 679 patients, angiographic follow-up was available in $65.5 \%$ of patients (445 patients with 561 lesions). Data are number (\%), unless otherwise indicated. Plus-minus values are means \pm SD.

Abbreviations: EES everolimus-eluting stent, R-ZES Resolute zotarolimus eluting-stent.

were no significant differences between EES and R-ZES, and the results were consistent across all subgroups, with no significant interaction p values (Figure 3).

\section{Propensity score matched group analysis}

Matching by propensity score with caliper width of 0.6 SDs yielded 249 EES patients matched to 249 R-ZES patients. Standardized differences of baseline clinical and angiographic characteristics were less than $10 \%$, and both groups were more balanced than before matching, with the exception of bifurcation lesion (percent standardized difference 12.91\%, Additional file 1: Table S4). The comparable incidences of clinical outcomes were corroborated in propensity score matched group analysis. The adjusted hazard ratio for TLF and POCO were 0.875 (95\% CI 0.427 - 1.793; $\mathrm{p}=0.715)$ and 1.029 (95\% CI $0.642-1.650 ; \mathrm{p}=0.904)$, respectively, for EES over R-ZES (Table 5). Among the propensity-score matched population, 325 patients $(65.3 \%$ 


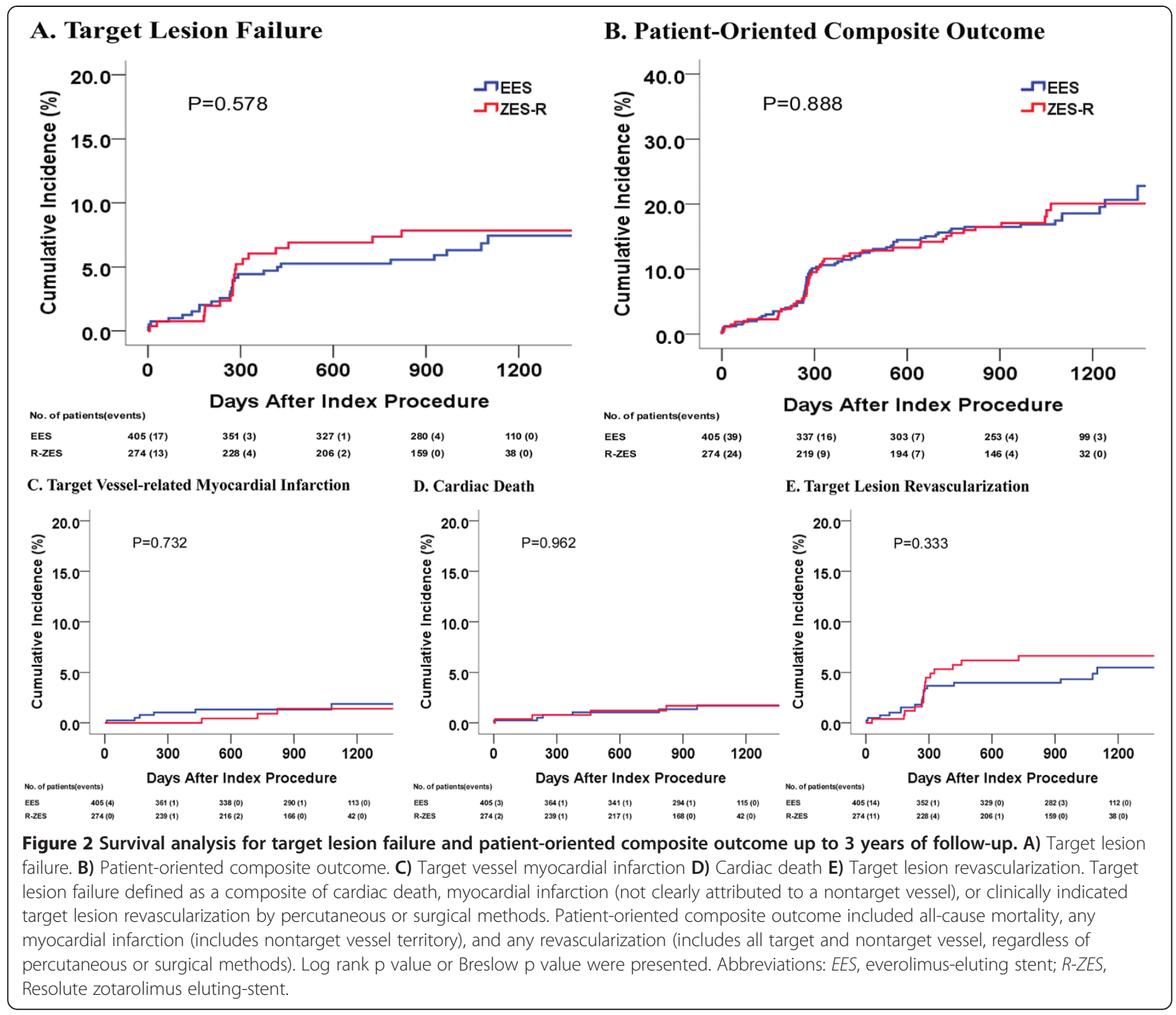

of 498 patients) performed 9-month follow-up angiography. Angiographic outcomes including in-stent and insegment late loss, and the rate of binary restenosis were comparable between the two groups (data not shown).

\section{Discussion}

This observational study compared the clinical and angiographic outcomes of two new-generation DES-the Xience V EES and the Resolute ZES-in an unselected patient population without exclusion criteria. There was no significant difference in the primary angiographic outcome, in-segment late loss at 9 months, between the two stent groups. The stent- and patient-related clinical outcomes (TLF and POCO, respectively) were comparable up to 3 years of follow-up, which were corroborated by the similar results from the propensity score matched cohort.

In our study, angiographic follow-up data were available in a relatively larger proportion of patients (445 among
679 patients, 65.5\%) compared with previous RCT analyzing the angiographic outcomes of EES and R-ZES in allcomers population (RESOLUTE All Comers trial (272 patients among 2292 patients, 11.9\%) [10]. To the best of our knowledge, this study includes the largest angiographic cohort for the comparison of EES and R-ZES. Although there were several significant differences in baseline clinical and angiographic characteristics between the two groups, which is an inherent limitation of nonrandomized studies, the angiographic outcomes, not only the binary restenosis but also the in-stent or in-segment late loss at 9 months, were comparable. Our angiographic follow-up data, performed in a relatively large patient population with complex coronary anatomy, support the previous result of RESOLUTE ALL Comers trial, which demonstrated no difference between EES and R-ZES in inhibitory effect on neointimal hyperplasia [10]. With regard to the differences in baseline clinical and angiographic 
Table 4 Clinical outcomes in crude population up to 3 years of follow-up (Kaplan-Meier estimates and log-rank p value) ${ }^{*}$

\begin{tabular}{|c|c|c|c|}
\hline & EES $(N=405)$ & R-ZES (N = 274) & $P$ value \\
\hline All cause death & $4.6 \%(16)$ & $3.9 \%(9)$ & 0.753 \\
\hline Cardiac death & $1.7 \%(6)$ & $1.7 \%(4)$ & 0.962 \\
\hline Any myocardial infarction & $2.1 \%(7)$ & $1.9 \%(4)$ & 0.858 \\
\hline Target vessel & $1.8 \%(6)$ & $1.4 \%(3)$ & 0.732 \\
\hline Non Target vessel & $0.3 \%(1)$ & $0.4 \%(1)$ & 0.760 \\
\hline Ml due to ST & $1.0 \%(3)$ & $1.4 \%(3)$ & 0.564 \\
\hline Target lesion revascularization & $5.6 \%(18)$ & $6.6 \%(16)$ & 0.333 \\
\hline Target vessel revascularization & $7.7 \%(26)$ & $8.3 \%(20)$ & 0.539 \\
\hline Any revascularization & $19.2 \%(54)$ & $17.4 \%(37)$ & 0.603 \\
\hline Target lesion failure $^{\dagger}$ & $7.5 \%(25)$ & $7.9 \%(19)$ & 0.578 \\
\hline Patient-oriented composite outcome ${ }^{\ddagger}$ & $22.8 \%(69)$ & $20.1 \%(44)$ & 0.888 \\
\hline Definite ST & $1.3 \%(4)$ & $0.9 \%(2)$ & 0.789 \\
\hline Acute ( $0-1$ day) & $0.0 \%$ & $0.0 \%$ & NA \\
\hline Subacute (2-30 days) & $0.5 \%(2)$ & $0.0 \%$ & 0.249 \\
\hline Late (31-360 days) & $0.3 \%(1)$ & $0.0 \%$ & 0.418 \\
\hline Very late ( $\geq 361$ days) & $0.5 \%(1)$ & $0.9 \%(2)$ & 0.296 \\
\hline Probable ST & $0.3 \%(1)$ & $0.9 \%(2)$ & 0.344 \\
\hline Acute (0-1 day) & $0.3 \%(1)$ & $0.0 \%$ & 0.411 \\
\hline Subacute (2-30 days) & $0.0 \%$ & $0.4 \%(1)^{\S}$ & 0.221 \\
\hline Late (31-360 days) & $0.0 \%$ & $0.0 \%$ & NA \\
\hline Very late ( $\geq 361$ days) & $0.0 \%$ & $0.5 \%(1)$ & 0.215 \\
\hline Definite/Probable ST & $1.5 \%(5)$ & $1.8 \%(4)$ & 0.741 \\
\hline
\end{tabular}

* Clinical outcomes were presented as cumulative incidence (Kaplan-Meier estimates, \%) of primary and secondary clinical outcomes calculated. Numbers of total events are presented in parentheses. $P$ values are log-rank $p$ value or Breslow $p$ value.

† Target lesion failure defined as a composite of cardiac death, myocardial infarction (not clearly attributed to a nontarget vessel), or clinically indicated target lesion revascularization by percutaneous or surgical methods at 3 years.

₹ Patient-oriented composite outcomes included all-cause mortality, any myocardial infarction (includes nontarget vessel territory), and any revascularization (includes all target and nontarget vessel, regardless of percutaneous or surgical methods).

${ }^{\S}$ Subacute stent thrombosis, presented with sudden cardiac arrest which occurred at 6 days after percutaneous coronary intervention.

Abbreviations: EES everolimus-eluting stent, MI myocardial infarction, R-ZES Resolute zotarolimus eluting-stent, ST stent thrombosis, EES everolimus-eluting stent.

characteristics between the two groups, selection bias might stem from the operator's experiences with the stent utilized. We postulate that the preference for EES in left main and restenotic lesions may be explained by longer experience with EES, which has been introduced earlier than R-ZES. In contrast, the previous experience with ZES (Endeavor ${ }^{\circ}$ Splint) with better deliverability compared to the first generation DES may have contributed to favoring R-ZES in small and multivessel disease.

Previously, RESOLUTE All Comers trials reported that R-ZES and EES showed similar safety and efficacy outcomes up to 2-year follow-up [10,11]. Although welldesigned RCTs are the gold standard to evaluate safety and efficacy of therapeutic options, these may not reflect the actual clinical practice due to highly selective inclusion criteria. Even RESOLUTE All Comers trial-a RCT with an 'all-comers' design-was not able to enroll all consecutive patients, but included only $44 \%$ of them [13]. While we prepared this report, the result of TWENTE trial was published, and they also reported the similar clinical outcomes for both stent types at 1 year [11]. Although, they enrolled more than $80 \%$ of all eligible patients and $77 \%$ of the enrolled patients were with off-label indication for DES, they excluded acute ST-segment elevation MI patients. In this study, we tried to evaluate and reflect routine 'real world' clinical practice as much as possible and the patients were enrolled at the time of the index procedure without exclusion criteria. As a result, a variety of patients with differing clinical and angiographic characteristics, such as acute MI, severe LV dysfunction, left main coronary artery disease, small vessel disease, long lesions, or in-stent restenosis lesions, were included for this analysis. Notably, the overall proportion of acute coronary syndrome was $53.9 \%$ (366/679 patients), those with diabetes 


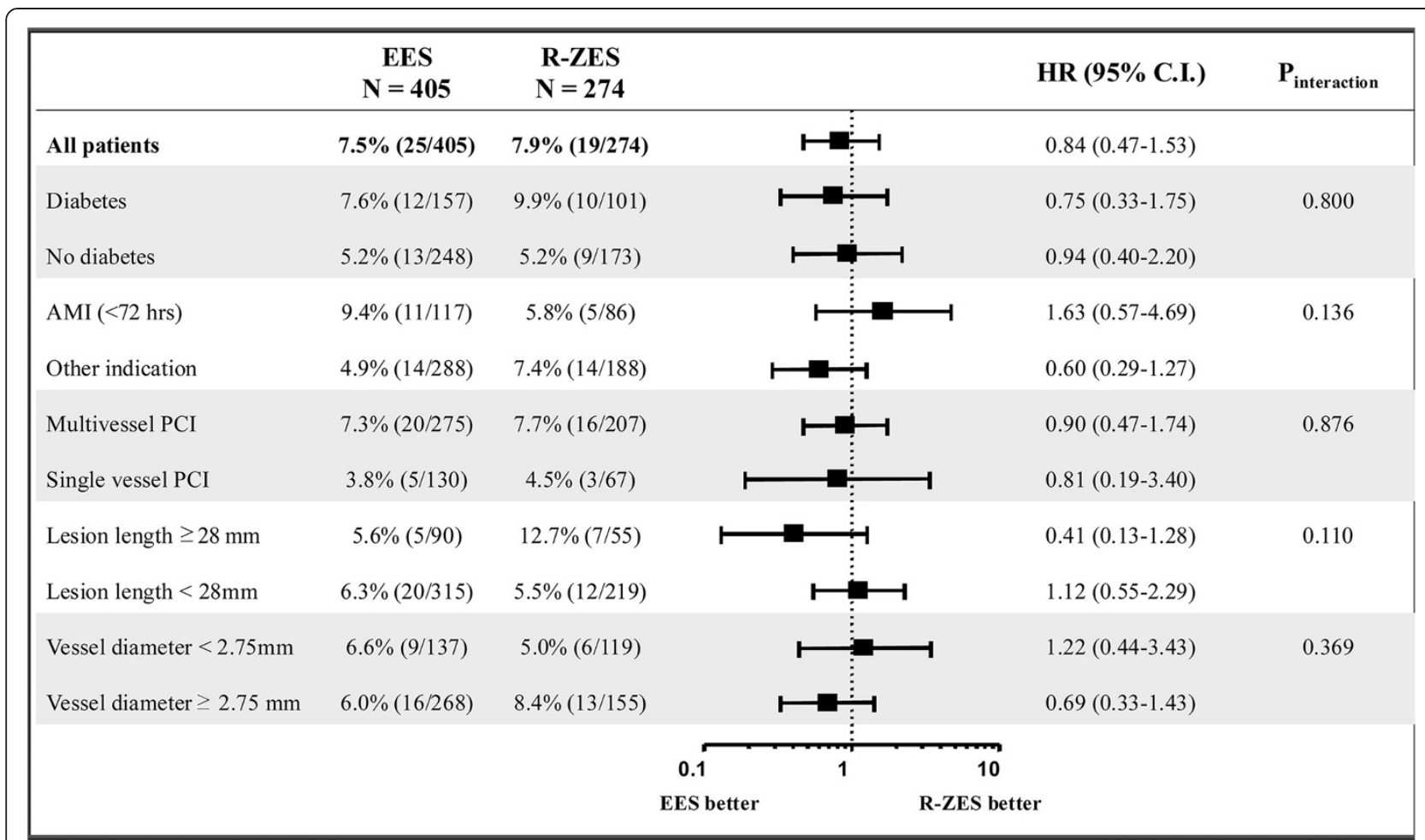

Figure 3 Subgroup analysis. Abbreviations: EES, everolimus-eluting stent; $R$-ZES, Resolute zotarolimus eluting-stent; $H R$, hazard ratio; $C l$, confidence interval; $A M I$, acute myocardial infarction; $P C l$, percutaneous coronary intervention.

mellitus was $38.0 \%$ (258/679 patients), and the majority of the population $(73.8 \%)$ had at least one criterion for complex patients or lesional characteristics. The large proportion of high-risk patients and lesions implies that our study population well reflects real-world practice in Korea without any exclusion or restriction.

It is noteworthy that, in a 2-year follow-up of the RESOLUTE All Comers trial, Silber et al. reported substantially higher rates of patient-related outcome than stent-related outcomes [11]. In agreement with the above study, we also noticed substantial difference between the rates of patientoriented composite outcomes and stent-related outcomes (TLF). These findings emphasize the importance of secondary prevention of cardiac risk factors and overall medical management of non-cardiac comorbidities [11].

\section{Limitations}

Some limitations of this study should be considered. First, this study was a non-randomized observational study using a single center registry data with a relatively small

Table 5 Clinical outcomes during follow-up period in the propensity score matched groups (249 pairs)

\begin{tabular}{lccccc}
\hline & EES & R-ZES & Adjusted HR & 95\% Cl & P value \\
\hline All cause death & $4.9(11)$ & $3.7(8)$ & 1.833 & $0.678-4.957$ & 0.232 \\
Cardiac death & $2.2(5)$ & $1.9(4)$ & 1.667 & $0.398-6.974$ & 0.484 \\
Any myocardial infarction & $2.7(5)$ & $2.0(4)$ & 1.000 & $0.202-4.955$ & $0.251-8.977$ \\
$\quad$ Target vessel & $2.2(4)$ & $1.6(3)$ & 1.500 & 0.999 \\
Target lesion revascularization & $5.7(10)$ & $7.2(16)$ & 0.533 & 0.657 \\
Target vessel revascularization & $7.4(14)$ & $9.1(20)$ & 0.706 & $0.337-1.478$ & 0.158 \\
Any revascularization & $22.3(35)$ & $18.6(36)$ & 0.833 & 0.151 \\
Target lesion failure & $8.4(16)$ & $8.6(19)$ & 0.875 & $0.427-1.793$ \\
Patient-oriented outcome & $26.4(46)$ & $21.1(42)$ & 1.029 & $0.642-1.650$ & 0.715 \\
\hline
\end{tabular}

* Hazard ratio was calculated with stratified Cox proportional hazard regression, values are hazard ratio of EES compared with R-ZES.

Abbreviations: $\mathrm{Cl}$ confidence interval, EES everolimus-eluting stent, $H R$ hazard ratio, $R$-ZES Resolute zotarolimus-eluting stent. 
number of patients and was not sufficiently powered to compare clinical outcomes between two stent groups due to limited sample size and low event rates. Second, even though we used propensity score matching and stratified Cox proportional hazard regression modeling to minimize the allocation bias and control for potential confounding variables, the possibilities of uncontrolled and unknown confounding factors need to be considered. Third, because data were from observational registries, the clinical events may not have been captured with scrutiny and patient follow-up may not have been as tight as would be in RCTs. Although we analyzed clinical outcomes up to 3 years of follow-up, a considerable number was lost to follow-up during the second year of follow-up. This can also be another source of bias and may explain lower TLF rate compared with that of RESOLUTE All Comer study at 2 year. However, censoring distributions of the two groups for the clinical outcomes were similar and little influence on the comparisons of two groups is expected. Fourth, the criteria of complex patients or lesional characteristics could not include homogeneous patient population. For example, a patient with severe renal insufficiency which has (at the same time) an acute MI due to left main disease is really different from a patient which receives a stent in an obtuse marginal artery because of in-stent re-stenosis, but both patients would be represented as the same complex group. Fifth, QCA analysis was not performed by an independent core laboratory, but rather by a single analyst. Although the analyst was blinded to the allocated stent group, systematic error cannot be completely excluded. In addition, there were no available data about intravascular ultrasound guidance PCI or the use of post-adjunctive balloon which is important for the optimal procedure. At last, a relatively high number of clinical events occurred around the ninth month during the follow-up, when the follow-up angiography was performed. It has been demonstrated that mandatory angiographic follow-up increases rates of revascularization [20]. We also speculate that the so-called 'oculo-stenotic reflex' may have contributed to the revascularization rates in this study. Therefore the present results cannot be directly extrapolated to routine clinical practice where mandatory follow-up angiography is not performed.

\section{Conclusion}

In Korean patients undergoing new-generation DES implantation for coronary artery disease, EES and R-ZES showed similar angiographic outcomes at 9 months and comparable clinical outcomes during 2.8 years of median follow-up. This study was only powered in comparison of angiographic outcome, 9-month in-segment late loss. For the comparison of clinical outcomes, larger study with adequate patient's number is warranted.

\section{Additional files}

Additional file 1: Table S1. Independent Variables Used in the Propensity-Score Model. Table S2. Baseline Clinical and Angiographic Characteristics of the Patients with Follow-up Angiography. Table S3. Detailed Description of Stent Thrombosis. Table S4. Baseline Clinical and Angiographic Characteristics after Propensity Score Matching.

\section{Competing interests}

Financial/nonfinancial disclosures: The authors have reported that no potential conflicts of interest exist with any companies/organizations whose products or services may be discussed in this article.

\section{Authors' contributions}

Each author has participated in this research as follows. JML - conception and design, data analysis \& interpretation, drafting of the manuscript; TJY conception and design, data analysis \& interpretation, critical review of the manuscript, final approval of the manuscript submitted; JJP - critical review of the manuscript; IYO - critical review of the manuscript; $\mathrm{CHY}$ - critical review of the manuscript; JWS - data analysis \& interpretation, critical review of the manuscript; YSC - critical review of the manuscript; GYC - critical review of the manuscript; $I H C$ - critical review of the manuscript; DJC critical review of the manuscript, final approval of the manuscript submitted. All authors read and approval the final manuscript.

\section{Author details}

${ }^{1}$ Division of Cardiovascular, Department of Internal Medicine, College of Medicine, Seoul National University and Cardiovascular Center, Seoul National University Hospital, Seoul, Korea. ${ }^{2}$ Division of Cardiology, Department of Internal Medicine, College of Medicine, Seoul National University and Cardiovascular Center, Seoul National University Bundang Hospital, Seongnam-si, Gyeonggi-do, Korea.

Received: 1 March 2013 Accepted: 3 September 2013

Published: 8 September 2013

\section{References}

1. Serruys PW, Kutryk MJ, Ong AT: Coronary-artery stents. N Engl J Med 2006, 354(5):483-495.

2. Stettler C, Wandel S, Allemann S, Kastrati A, Morice MC, Schomig A, Pfisterer ME, Stone GW, Leon MB, de Lezo JS, et al: Outcomes associated with drug-eluting and bare-metal stents: a collaborative network meta-analysis. Lancet 2007, 370(9591):937-948.

3. Stone GW, Moses JW, Ellis SG, Schofer J, Dawkins KD, Morice MC, Colombo A, Schampaert E, Grube E, Kirtane AJ, et al: Safety and efficacy of sirolimus- and paclitaxel-eluting coronary stents. N Engl J Med 2007 , 356(10):998-1008.

4. Kirtane AJ, Gupta A, lyengar S, Moses JW, Leon MB, Applegate R, Brodie B, Hannan E, Harjai K, Jensen LO, et al: Safety and efficacy of drug-eluting and bare metal stents: comprehensive meta-analysis of randomized trials and observational studies. Circulation 2009, 119(25):3198-3206.

5. Di Lorenzo E, Sauro R, Varricchio A, Carbone G, Cortese G, Capasso M, Lanzillo T, Manganelli F, Mariello C, Siano F, et al: Long-Term outcome of drug-eluting stents compared with bare metal stents in ST-segment elevation myocardial infarction: results of the paclitaxel- or sirolimus-eluting stent versus bare metal stent in primary angioplasty (PASEO) randomized trial. Circulation 2009, 120(11):964-972.

6. Cook S, Ladich E, Nakazawa G, Eshtehardi P, Neidhart M, Vogel R, Togni M, Wenaweser $P$, Billinger $M$, Seiler $C$, et al: Correlation of intravascular ultrasound findings with histopathological analysis of thrombus aspirates in patients with very late drug-eluting stent thrombosis. Circulation 2009, 120(5):391-399.

7. Mauri L, Hsieh WH, Massaro JM, Ho KK, D'Agostino R, Cutlip DE: Stent thrombosis in randomized clinical trials of drug-eluting stents. $N$ Engl J Med 2007, 356(10):1020-1029.

8. Finn AV, Kolodgie FD, Harnek J, Guerrero LJ, Acampado E, Tefera K, Skorija K, Weber DK, Gold HK, Virmani R: Differential response of delayed healing and persistent inflammation at sites of overlapping sirolimus- or paclitaxel-eluting stents. Circulation 2005, 112(2):270-278. 
9. Akin I, Schneider H, Ince H, Kische S, Rehders TC, Chatterjee T, Nienaber CA: Second- and third-generation drug-eluting coronary stents: progress and safety. Herz 2011, 36(3):190-196.

10. Serruys PW, Silber S, Garg S, van Geuns RJ, Richardt G, Buszman PE, Kelbaek H, van Boven AJ, Hofma SH, Linke A, et al: Comparison of zotarolimus-eluting and everolimus-eluting coronary stents. N Engl J Med 2010, 363(2):136-146.

11. Silber $S$, Windecker $S$, VranckX P, Serruys PW: Unrestricted randomised use of two new generation drug-eluting coronary stents: 2-year patient-related versus stent-related outcomes from the RESOLUTE All Comers trial. Lancet 2011, 377(9773):1241-1247.

12. von Birgelen C, Basalus MW, Tandjung K, van Houwelingen KG, Stoel MG, Louwerenburg JH, Linssen GC, Said SA, Kleijne MA, Sen H, et al: A randomized controlled trial in second-generation zotarolimus-eluting resolute stents versus everolimus-eluting Xience $\mathrm{V}$ stents in real-world patients: the twente trial. J Am Coll Cardiol 2012, 59(15):1350-1361.

13. de Boer SP, Lenzen MJ, Oemrawsingh RM, Simsek C, Duckers HJ, van der Giessen WJ, Serruys PW, Boersma E: Evaluating the 'all-comers' design: a comparison of participants in two 'all-comers' $\mathrm{PCl}$ trials with non-participants. Eur Heart J 2011, 32(17):2161-2167.

14. Park KW, Lee JM, Kang SH, Ahn HS, Yang HM, Lee HY, Kang HJ, Koo BK, Cho J, Gwon HC, et al: Safety and efficacy of second-generation everolimus-eluting Xience V stents versus zotarolimus-eluting resolute stents in real-world practice: patient-related and stent-related outcomes from the multicenter prospective excellent and Resolute-Korea registries. J Am Coll Cardiol 2013, 61(5):536-544.

15. Serruys P, Foley D, De Feyter PJ: Quantitative coronary angiography in clinical practice. Dordrecht, the Netherlands: Springer; 1994.

16. Cutlip DE, Windecker S, Mehran R, Boam A, Cohen DJ, van Es GA, Steg PG, Morel MA, Mauri L, Vranckx P, et al: Clinical end points in coronary stent trials: a case for standardized definitions. Circulation 2007, 115(17):2344-2351.

17. Stefanini GG, Serruys PW, Silber S, Khattab AA, van Geuns RJ, Richardt G, Buszman PE, Kelbaek H, van Boven AJ, Hofma SH, et al: The impact of patient and lesion complexity on clinical and angiographic outcomes after revascularization with zotarolimus- and everolimus-eluting stents: a substudy of the RESOLUTE All Comers Trial (a randomized comparison of a zotarolimus-eluting stent with an everolimus-eluting stent for percutaneous coronary intervention). J Am Coll Cardiol 2011, 57(22):2221-2232.

18. Gu XS, Rosenbaum PR: Comparison of multivariate matching methods: structures, distances, and algorithms. J Comput Graph Stat 1993, 2(4):405-420.

19. Cohen J: In Statistical power analysis for the behavioral sciences. Edited by Hillsdale NJ. England: Lawrence Erlbaum Associates, Inc; 1977.

20. Pinto DS, Stone GW, Ellis SG, Cox DA, Hermiller J, O'Shaughnessy C, Mann JT, Mehran R, Na Y, Turco M, et al: Impact of routine angiographic follow-up on the clinical benefits of paclitaxel-eluting stents: results from the TAXUS-IV trial. J Am Coll Cardiol 2006, 48(1):32-36.

doi:10.1186/1471-2261-13-65

Cite this article as: Lee et al.: Comparison of 9-month angiographic outcomes of Resolute zotarolimus-eluting and everolimus-eluting stents in a real world setting of coronary intervention in Korea. BMC

Cardiovascular Disorders 2013 13:65.

\section{Submit your next manuscript to BioMed Central and take full advantage of:}

- Convenient online submission

- Thorough peer review

- No space constraints or color figure charges

- Immediate publication on acceptance

- Inclusion in PubMed, CAS, Scopus and Google Scholar

- Research which is freely available for redistribution 